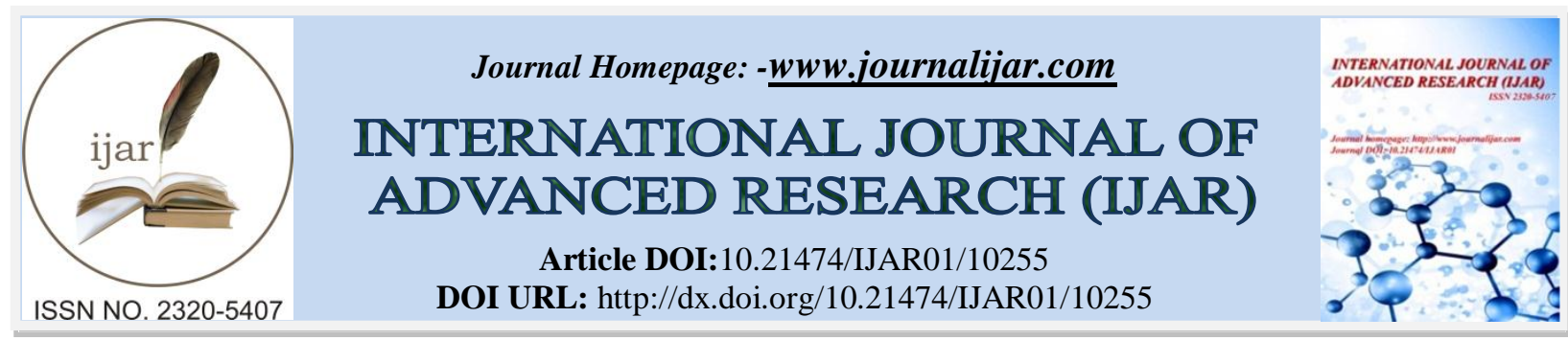

RESEARCH ARTICLE

\title{
COMPARISON OF APICALLY EXTRUDED DEBRIS PRODUCED BY WAVEONE GOLD AND PROTAPER NEXT AFTER USING MECHANICAL OR MANUAL GLIDE PATH TECHNIQUES
}

\author{
Shaimaa Rabea ${ }^{1}$, Wael Hussein Kamel ${ }^{2}$, Mohsen M. Nour El Din ${ }^{2}$ and Nehal Farouk Sharaf ${ }^{3}$ \\ 1. Restorative \& Dental Material Department, National Research Centre. \\ 2. Endodontic Department, Faculty of Dental Medicine for Girls, Al-Azhar University. \\ 3. Restorative \& Dental Material Department, National Research Centre. Orcid number 0000-0001-6505-2854.
}

\section{Manuscript Info}

\section{Manuscript History}

Received: 14 October 2019

Final Accepted: 16 November 2019

Published: December 2019

Key words:-

Apically Extruded Debris, Pro Taper

Next, Wave One Gold, Path Files, KFiles

\section{Abstract}

Aim: To evaluate the amount of apically extruded debris produced byWaveOne Gold (WOG) and ProTaper Next (PTN) after using mechanical or manual glide path techniques.

Methodology: Forty freshly extracted human permanent mandibular first molars were collected and randomly assigned into one of the two main groups (I\&II) ( $\mathrm{n}=20$ for each group) according to the instrumentation techniques used using either the WOG or the PTN, then each group was randomly subdivided into two subgroups (A\&B) ( $n=10$ for each subgroup) according to the type of instrument used to create the glide path using either the PathFiles (PF) or the K-Files (KF). During instrumentation, the apically extruded debris (AED) was collected into pre-weighed Eppendorf tubes. Then tubes were incubated at $70^{\circ} \mathrm{C}$ for 5 days. The net weight of the apically extruded debris was calculated in gram by subtracting the pre-weight of the empty tubes from the post-weight. The data were statistically analyzed.

Results: Using the WOG/KF was statistically significantly associated with the highest amount of the AED followed by the PTN/KF and WOG/PF with no significant difference between them while the PTN/PF was statistically significantly associated with lowest amount of the AED.

Conclusions: Although all systems caused apical extrusion of debris, using the multi-file continuous rotary system with mechanical glide path files could be considered as a promising and reliable approach to prepare the root canal with less amount of debris extruded apically.

Copy Right, IJAR, 2019,. All rights reserved.

\section{Introduction:-}

Root canal treatment evidently lessens pain prevalence and severity when properly carried out, though the severity of post operative pain may sometimes exceed the severity of the pretreatment one ${ }^{(1)}$.

Post-endodontic pain may be triggered by the apical extrusion of debris through out the chemo-mechanical instrumentation that may provoke an inflammatory response ${ }^{(2)}$. New advances are present nowadays in kinematics of canal shaping either rotation or reciprocation file systems. 
The ProTaper Next (PTN) system poses shaping advantages owing to its M-Wire technology, variable tapered design within each instrument and a distinctive offset mass of rotation. The unique design along with the characteristic swaggering wave of motion was reported to participate in extrusion of dentin chips and debris in a coronal direction ${ }^{(3)}$. However, the fact of being a multi-file system was a concern to some investigators.

The WaveOne Gold (WOG) system is a single super-elastic NiTi file instrument setup that executes reciprocating motion during canal preparation. The reciprocating movement minimizes torsional and flexural stresses. ${ }^{(4)}{ }^{(5)}$ Despite its advantages, some investigations informed greater debris extrusion and risk of postoperative pain associating the reciprocating instrumentation techniques in comparison to the continues rotation instrumentation techniques ${ }^{(4)}$.

Canal scouting and preflaring are believed to be a crucial phase and the initial stage of canal instrumentation and they are essential for the safer usage of NiTi rotary instruments ${ }^{(6)}$. NiTi rotary PathFiles (PFs) have been introduced for mechanical preflaring, this approach showed to be less invasive and less technique sensitive compared with manual preflaring performed with stainless-steel K-files $(\mathrm{KFs}){ }^{(6)}$.

This motivated our desire to assess the influence of single and multiple NiTi rotary file systems on apical extrusion of debris after root canal instrumentation using the mechanical and manual glide path techniques.

\section{Materials and Methods:- \\ Teeth selection and preparation:-}

Forty freshly extracted human permanent mandibular first molars were collected from patients following approval of the Research Ethics Committee (REC) of Faculty of Dental Medicine for Girls, Al-Azhar University, Egypt (REC code 16/014). Then the teeth were selected to fulfill certain inclusion and exclusion criteria. The Inclusion criteria involved teeth with intact roots and mature apices, two separate mesial canals that terminate with two separate apical foramina, according to Schneider's technique ${ }^{(7)}$, and the mesiobuccal and mesiolingual canals should have curvature range of $\left(25^{\circ}-40^{\circ}\right)$. While, the exclusion criteria involved teeth with previous root canal treatment, Teeth with evidence of root caries, cracks or fractures, teeth with any abnormalities as internal, external resorption or root canal calcification, teeth with open apices.

All teeth were scaled and radiographed from the buccal and proximal views to exclude any abnormalities. Vertical roots separation was then carried out using diamond disc followed by horizontal sectioning of the crowns until equal lengths were obtained. The length of all roots was standardized to $17 \mathrm{~mm}$. All the external root surfaces of the mesial roots were covered with two layers of transparent nail polish except for $1 \mathrm{~mm}$ around the apical foramen. Apical patency was performed with \#10 stainless steel manual K- file until visible at the apical foramen and the working length was determined by subtracting $1 \mathrm{~mm}$ from this length. The patency and working length determination were performed separately for the mesiobuccal and mesiolingual canals. To avoid any bias caused by differences in the initial width, roots in which \# $15 \mathrm{~K}$-file fitted tightly at the apical foramen were selected while roots with apical diameter larger than \#15 were excluded.

\section{Preparation of the debris collection assembly:-}

Debris collection was performed using the technique initially described by Fairbourn et al. $(1987)^{(8)}$ and modified by Myers \& Montgomery $(1991)^{(9)}$.

For each sample, an Eppendorf tube was labeled and the covers of the Eppendorf tubes were removed then the tubes were individually weighed using a microbalance to obtain the initial weight. Three consecutive measurements were taken for each Eppendorf tube, and the mean values were recorded.

A hole was created on the cap (lid) of an Eppendorf tube with round bur, and the root was inserted under pressure through this cover, up to the cementoenamel junction (CEJ) and fixed in the tube lid with cyanoacrylate adhesive in order to create a hermetic seal to avoid leakage of the irrigant into the tube. Then each cap (cover) with the root was attached to its Eppendorf tube (Figure: 1\&2).

Glass vials with rubber stoppers were adjusted by using a round bur and tapered stone to create a hole through the center of each stopper. Then, each Eppendorf tube was fitted into a vial to hold the set-up during instrumentation (Figure: $1 \& 2$ ). The gaps surrounding the hole, the Eppendorf tube were carefully filled with adhesive. The vial was 
covered by opaque wrap to prevent the operator from viewing debris extrusion during the instrumentation phase minimizing possible bias (Figure:1\&2).

The apparatus was sealed with a rubber sheet along with a clamp in order to create a hermetic seal and to avoid accidental leakage of the irrigating solution into the tube during the experiment (Figure: 1\&2). A 27-G needle was folded and inserted in the Eppendorf lid next to the fitted root as a drainage cannula and to equalize the internal and external pressures.

The entire apparatus was handled only by the vial and hand held vertically during instrumentation. At no time was the Eppendorf tube touched by the fingers.

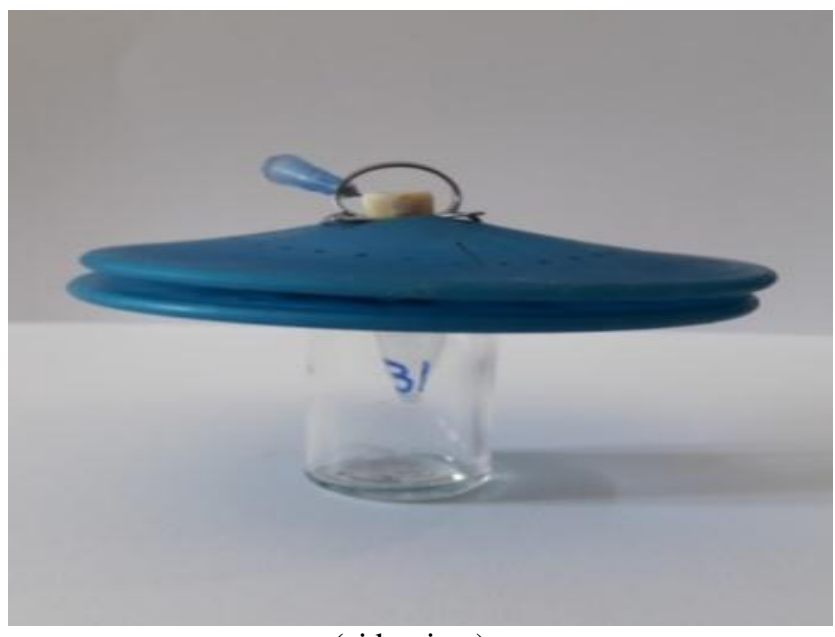

(side view):-

Fig (1):- A photograph showing an experimental model used as debris collection assembly.

1. A bent 27 gauge needle

2. Clamp

3. Rubber dam

4. Rubber stopper

5. Mesial root of mandibular molar

6. Eppendorf tube

7. Glass vial

8. Apically extruded debris

9. Opaque wrap

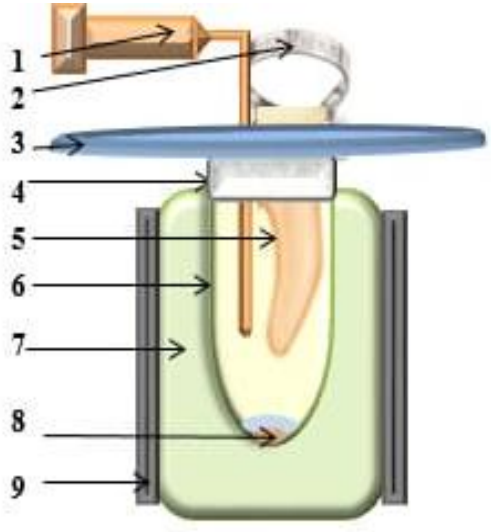

Fig (2):- Schematic representation showing the components of the modified debris collection assembly.

\section{Samples grouping and root canal preparation procedures:-}

After specimens numbering, Random Sequence Generator was used to make the computerized sequence generation for the roots' numbers. The roots of forty molar teeth $(n=40)$ were randomly assigned to one of the two main groups (I\&II) according to the instrumentation techniques used then each group (I\&II) was randomly subdivided into two subgroups (A\&B) according to the type of instrument used to create the glide path into:

\section{Group I / Subgroup A:-}

The root canals in this group $(\mathrm{n}=10)$ were instrumented using the reciprocating single file WaveOne Gold system (DentsplyMaillefer, USA) preceded by a mechanical glide path using the NiTi rotary PathFiles (PF) (DentsplyMaillefer, USA). 
PF \#1 'purple' (13/0.02) then PF \#2 'white' (16/0.02) and PF \#3 'yellow' (19/0.02) were used at WL by using an endodontic engine 'X-Smart Plus' (DentsplyMaillefer, USA) with 16:1 contra angle at the suggested setting '300 $\mathrm{rpm}$ on display, $5 \mathrm{Ncm}$ '. The PFs were used in continuous rotation with an outward brushing motion. Then the root canals were instrumented using the reciprocating single file system WaveOne GOLD (25/.07), in a pecking motion, by a dedicated reciprocating motor (X-Smart Plus) that was used with the manufacturer configuration set-up. Based on the initial apical binding file, the master apical file tip size for WOG was standardized at \#25 for narrow canals and WOG Medium (35/.06) for wide canals.

\section{GroupI / Subgroup B:-}

The root canals in this group $(n=10)$ were instrumented using the reciprocating primary WaveOne Gold single file preceded by a manual glide path using the stainless steel (St.St.) hand K-type File \#15, \#17, \#20 ( Mani Inc, Utsunomiya, Tochigi, Japan). KF \#15 (15/0.02) was used, then KF \#17 (Medium sized K-file) (17/0.02) and KF \#20 (20/0.02) with an initial watch winding motion to the point of resistance and then are gently pulled out to remove restricted dentin and debris then followed by a vertical motion till the dentin wall wear away and the file advanced to the working length. Then the root canals were instrumented using the WOG.

\section{GroupII/ subgroup A:-}

The root canals in this group were instrumented using the ProTaper Next (PTN) system (DentsplyMaillefer, USA) preceded by a mechanical glide path using the NiTi rotary PathFiles (PF). The ProTaper Next (PTN) system was used according to manufacturer instructions with crown down technique. PTN system was used in full sequence rotation with lateral brushing using a torque-controlled endodontic motor (X-Smart Plus) at $300 \mathrm{rpm}$ and a torque of 2.6 Ncm. Based on the initial apical binding file, the master apical file tip size for PTN was standardized at \#25 for narrow canals and PTN X4 (40/.06) for wide canals.

\section{GroupII/ Subgroup B:-}

The root canals in this group $(n=10)$ were instrumented using the rotating multi-file system using the ProTaper Next (PTN) system preceded by a manual glide path using the K-type Files.

During the instrumentation procedure, the apical patency was checked using a $10 \mathrm{~K}$-file and the canal was reirrigated with distilled water. After each instrument, irrigation was performed using $2 \mathrm{~mL}$ of distilled water with a total of $6 \mathrm{~mL}$ of irrigant for the glide path stage and a total of $6 \mathrm{~mL}$ for the canal instrumentation stage. A double side-port irrigation needle 'NaviTipSideport $31 \mathrm{G}$ was inserted without binding or encountering resistance moving in an up-and-down motion dynamically during irrigation with minimum pressure. Surgical suction was placed close to the access cavity to aspirate the excess irrigating solution. Aspiration and irrigation were performed in exactly the same manner for all specimens.

On completion of the canal preparation, the canals were irrigated with $3 \mathrm{~mL}$ of distilled water as a final irrigation, dried with paper points. The stopper, needle, and the root were removed from the Eppendorf tube. The debris adherent to the external surface of the root apex was collected by washing the root with $1 \mathrm{~mL}$ distilled water in the tube. A total amount of $20 \mathrm{~mL}$ of the irrigating solution was used for each tested group.

\section{Evaluation of apically extruded debris:-}

The tubes were then removed from the vials and were stored in an incubator at $70{ }^{\circ} \mathrm{C}$ for 5 days to evaporate the distilled water before weighing the dry debris. Tubes were then kept at room temperature for $24 \mathrm{~h}$ in an incubator with anhydrous $\mathrm{CaCl}_{2}$ crystals to absorb the moisture present in incubator before final weighing. Such a standard protocol was followed taking into account the fact which dictates that even moisture in the air may influence the final weight.

Evaluation was completed by a second examiner blinded to group assignment. After the incubation period, weight calculation was performed using the same sensitive balance to obtain the final weight of each tube containing the dry extruded debris. Three consecutive weights were obtained for each tube, and the mean value was calculated. The net weight of the apically extruded debris (AED) was determined by subtracting the original weight of the empty Eppendorf tube (pre-weight) from the gross weight of the Eppendorf tube containing the dry extruded debris (postweight). The weight of the extruded debris was measured in gram using the microbalance. The data were statistically analyzed 


\section{Statistical analysis:-}

Data were presented as mean, standard deviation (SD) values. Dependent t-test was used to show the effect of single and multiple NiTi rotary file systems on apical extrusion of debris. Two-way ANOVA was used to show the effect of the different shaping files and glide path creating files usage for different tested parameters. The significance level was set at $(\mathrm{P} \leq 0.05)$. Statistical analysis was performed with IBM $^{1 \circledast}$ SPSS $^{\circledR}$ Statistics Version 25 for Windows.

\section{Results:-}

"Hand K-type File/WaveOne Gold" had statistically significantly $(\mathrm{P} \leq 0.001)$ the highest mean value $( \pm \mathrm{SD})$ of the apically extruded debris $(0.00120 \pm 0.00020 \mathrm{~g})$, followed by"Hand K-type File/ ProTaper Next" $(0.00083 \pm 0.00014$ g) and "Rotary PathFile/WaveOne Gold" $(0.00076 \pm 0.00019 \mathrm{~g})$. There was no statistical significant difference between them. While, "Rotary PathFile / ProTaper Next" had statistically significantly $(\mathrm{P} \leq 0.001)$ the lowest mean value $( \pm \mathrm{SD})$ of the apically extruded debris $(0.00057 \pm 0.00016 \mathrm{~g})$. (Table $: 1)$

Table 1:- Descriptive statistics and test of significance difference for the comparison between the mean values of the apically extruded debris for the different interactions.

\begin{tabular}{|c|c|c|c|c|}
\hline \multirow[b]{2}{*}{ Groups } & \multicolumn{2}{|c|}{ Apically extruded debris (g) } & \multirow[t]{2}{*}{ Rank } & \multirow[t]{2}{*}{$p$-value } \\
\hline & Mean & SD & & \\
\hline 'WaveOne Gold/ Rotary PathFile’' & 0.00076 & 0.00019 & $\mathrm{~b}$ & \multirow[t]{4}{*}{$\leq 0.001 *$} \\
\hline 'WaveOne Gold/ Hand K-type File' & 0.00120 & 0.00020 & $\mathrm{a}$ & \\
\hline 'ProTaper Next / Rotary PathFile' & 0.00057 & 0.00016 & $\mathrm{c}$ & \\
\hline 'ProTaper Next / Hand K-type File' & 0.00083 & 0.00014 & $\mathrm{~b}$ & \\
\hline
\end{tabular}

Additionally, ANOVA test revealed that whether using the manual or mechanical glide path technique, the reciprocating single file system 'WaveOne Gold' showed a statistically significantly $(\mathrm{P} \leq 0.001)$ higher mean value of the apically extruded debris than the rotating multi-file system 'ProTaper Next'. In addition, whether using the single or multiple file systems, the manual glide path "hand K-type files" showed a statistically significantly $(\mathrm{P} \leq 0.001)$ higher mean value $( \pm \mathrm{SD})$ of the apically extruded debris than the mechanical glide path "rotary PathFiles".

\section{Discussion:-}

The main objective of root canal therapy is to clean the root canal system. Debris such as dentine chips, necrotic pulp tissue, microorganisms and irrigants may be extruded into the periradicular tissue during canal instrumentation ${ }^{(10)}$. The apical extrusion of infected debris is possibly one of the principle causes of post-operative pain and may have the potential of disrupting the balance between microbial aggression and host defense, resulting in episodes of acute exacerbations and flare ups ${ }^{(11)}$.

The purpose of the current study was to evaluate the influence of single and multiple NiTi rotary file systems on apical extrusion of debris after root canal instrumentation using the mechanical and manual glide path technique.

In the present study, mandibular molar teeth were used, and both mesio-buccal and mesio-lingual curved canals were prepared. This was in consistency with De-Deus et al.(2015) ${ }^{(4)}$ and Abdallah et al. (2017) ${ }^{(12)}$ that preferred using mesial roots of lower molars. Considering that, these canals are frequently narrow and might show accentuated curves that possibly will complicate the debridement and shaping procedures ${ }^{(12)}$. This was in an attempt to reduce the gap between the laboratorial settings and the challenging real-life clinical situations ${ }^{(4)}(12$

Considering that, the amount of extruded debris might be influenced by the final instrument size ${ }^{(13)}$ and for standardization in methodology,tip standardization was attempt. Both systems had a tip diameter equivalent to size 25 , thus, the size of apical enlargement of the experimental groups were equivalent. ${ }^{(14)}$ Increasing the size of canal preparation apically could result in decreased flexibility of the instruments and may increase the risk of canal transportation and apical extrusion of debris especially in curved canals ${ }^{(14)}$. 
Moreover, irrigation could be considered as one of the primary causes of apical extrusion of debris because instrumentation without irrigation does not produce any collectible debris ${ }^{(15)}(16)$. Sodium hypochlorite $(\mathrm{NaOCl})$ was not used in this study as an irrigant during the evaluation of the apically extruded debris ${ }^{(17)}$. On the other hand, the distilled water was used as an irrigant, for the significance of meticulous measurements ${ }^{(18)}$, to avoid any potential weight increase due to $\mathrm{NaOCl}$ crystal formation that could compromise the reliability of the results ${ }^{(20)(15)(19)}$.

The results of the current study showed that, the reciprocating system 'WOG' significantly extrudedmore debris than multi-file rotary system 'PTN'. The current results in general perspective might possibly be explained by differences in movement kinematics, design of the instrument and the number of files between systems ${ }^{(20)(19)(22)}$

The greater debris extrusion produced by the WOG system as revealed in our results compared to the PTN system could be attributed to the movement kinematics ${ }^{(23)}$. As the WOG was used in reciprocation movement that is formed by a wider cutting angle $\left(150^{\circ} \mathrm{CCW}\right)$ and a smaller releasing angle $\left(30^{\circ} \mathrm{CW}\right)^{(5)}$; as a consequence the flutes might not be able to remove the debris out in a coronal direction but forced them apically ${ }^{(24)}$. On the other hand, the PTN system was used in continuous rotation movement that was reported to improve movement of dentin chips out of the canal in coronal direction ${ }^{(25)}$.

The results of the current study were in similar to the results of Bürklein et al. (2012) ${ }^{(26)}$ Surakanti et al. $(2014)^{(10)}$ and Uzun et al. (2016) ${ }^{(29)}$ who reported that, the use of the reciprocating single-file system was associated with more debris extrusion than the full-sequence multi-file rotary system. Also,these elucidations were consistent with the three-Dimensional Micro-computed Tomography outcomes reported by Robinson et al. (2013) ${ }^{(25)}$.On the contrary, the findings of the current study disagree with those obtained byAbou El Nasr \& Gawdat (2017) ${ }^{(27)}$ and Tomer et al. $(2017)^{(28)}$ who reported that, the reciprocating single-file system 'WaveOne Gold' out performed the rotary system 'OneShape' instruments with less apically extruded debris.

In the current study the differences in extrusion of debris might be also attributed to the differences in geometrical design of each system. The WOG has a parallelogram cross section ${ }^{(5)}$, while PTN has a rectangular cross section ${ }^{(31)}$. Moreover, in the present study, tip standardization was attempted where as the tip diameter was equivalent to a size 25 for both systems. In spite of this, the instruments tapers in the apical $3 \mathrm{~mm}$ varied amongst the examined systems; WOG primary instrument has a 0.07 taper, while PTN X1 and X2 files have a 0.04 and 0.06 tapers, respectively. Such differences might have an effect on the extrusion end result ${ }^{(33)}$.

This was in agreement with Topcuglu et al.(2016) ${ }^{(20)}$ and Uzun et al. $(2016)^{(29)}$ who reported that, the larger tapers at the tips of the instrument 'like WOG' could result in more aggressive preparation of the root canals and more debris extrusion. In contrast the current results were in disagreement with Dincer et al $2017^{(34)}$ who reported less apical extrusion associated with WOG than the PTN and speculated that results to the movement kinematics rather than the design as the principal reason behind the positive effect on debris extrusion of the WOG.

Additionally, each WOG file has a semi-active guiding tip, which allows file penetration along the root canal. While the PTN files have non-cutting tips that function as a guide that enables the file to progress along canals without cutting also tends to avoid pushing the debris apically ${ }^{(11)}$. This was harmonious with Sowmya et al. $(2014)^{(11)}$ and Jain et al. (2015) ${ }^{(35)}$ who signified the role of the difference in the tip design of each system on the extrusion outcomes.

The swaggering movement might be generated as interplay between the progressive tapering, offset design and the continuous rotation kinematics. The swaggering motion of the ProTaper Next system serves to decrease the engagement between root canal wall and the file ${ }^{(18)}$. That motion reduces the stress generation during rotation and screw-in forces. Thus, travelling waves of motion were generated along the active part of the file while still providing more cross-sectional space for enhanced cutting, loading and successfully allowing the debris to travel out of a canal (coronally), compared to a file with a centered mass and axis of rotation ${ }^{(31)}$. It may also decrease the chances for the file packing the debris laterally, aiding in reducing the chances of canal blockage. This explain the smaller amount of extruded debris in PTN group in comparison to the WOG group ${ }^{(19)}$.

This came in agreement with Surakanti et al. $(2014)^{(10)}$, who stated that the same design 'offset' with different kinematics 'rotation, reciprocation' may lead to different outcomes. While these findings were in disagree with Çiçek et al. $(2016)^{(36)}$ and Costa et al. $(2018)^{(37)}$ who reported more extruded debris associated with the PTN when 
compared to the reciprocating single file systems. These inconsistent previous findings could be due to differences design of the instrument, and teeth used.

The formerly declared factors concurrently might have contributed for the greater debris transportation ${ }^{(26)}$ extrusion associated with the WOG system towards the apex in comparison to the PTN system ${ }^{(38)}$.

Regarding the influence of the instruments number on the apical extrusion of debris; in earlier in-vitro studies, it has been proclaimed that the greater the number of files utilized for mechanical preparation, the greater amount of extruded debris ${ }^{(39)}$ (40) (4). In the present study, the number of files used for canal preparation in the WOG and PTN was one and two files, respectively, however; The PTN systems caused less debris extrusion than the WOG system; hence the amount of extruded debris cannot be correlated with the number of files used thru root canal preparation ${ }^{(20)}$ but related to the type of movement and design of the instruments ${ }^{(20)}$. This was consistent with Topçuoğlu et al. (2016) ${ }^{(20)}$ who clarified that, the design of the instrument was verified to be the most significant factor for apical extrusion of debris after root canal preparation, regardless of the number of files.

The results of the current study revealed that, the manual glide path performed by St.St. hand K-type Files extruded significantly more debris than the mechanical glide path performed by NiTi rotary PathFiles. The current results could possibly be explained by differences in the movement kinematics and instrument geometric designs between systems $^{(41)(42)}$

The possible rationalization for more apical extrusion of debris in case of manual glide path instrumentation using $\mathrm{K}$-files is that, in the apical one third; the manual file acts as a piston ${ }^{(43)}$. This could feasibly induce greater pressure apically ${ }^{(4)}$. And account for the greater tendency of the file for pumping the irrigating solution and pushing the debris apically through the foramen, as limited space is available to urge debris out the canal in a coronal direction $^{(43)}$

On the other hand, in case of mechanical glide path instrumentation using PathFiles, the continuous rotation kinematics of the files combined with the outward brushing motion could improve coronal transportation of dentine chips and debris by acting like a screw conveyor. Accordingly, the debris trapped in the apical part of the NiTi file could be lifted efficiently in the coronal direction during rotation ${ }^{(45)}$. The results of this study were in accordance with $\mathrm{Ha}$ et al. $(2016)^{(41)}$,Abdallah et al. $(2017)^{(42)}$ who found that creating the glide path using NiTi rotary files produced lower amounts of debris extrusion than using manual St.St. K-files. On the contrary, the current results conflicting with Türker et al. $(2014)^{(46)}$ who informed that creation of a glide path using PathFiles before using rotational or reciprocal NiTi instrument, does not affect the apical extrusion of debris.

Additionally, the K-files are made of stainless steel alloy. Stainless steel alloy can be categorized inherently as rigid alloy ${ }^{(48)}$ that may increase the risk of transportation and debris extrusion in the apical part of curved root canals. That coordinate with Van der Vyver $(2011)^{(49)}$ and Ruddle et al. $(2014){ }^{(50)}$ who informed that, many partially or fully negotiated canals became iatroginically blocked, ledged, perforated, or partially transported when using size 15 or 20 St.St. hand K-files due to the stiffness of such instruments especially in curved canals. On the contrary, the PathFiles are made of Nickel Titanium alloys. Nickel Titanium alloy is super-elastic, 2-3 times more than stainless steel files, due to their very low modulus of elasticity. Besides, NiTi alloy is well known for its inherent flexibility relative to stainless steel alloy ${ }^{(51)(52)}$. Consequently, the NiTiPathFiles might have maintained the original canal anatomy and increased the efficiencies of debris removal with minimal extrusion during glide-path preparation in the curved root canals ${ }^{(49)(51)}$.

Besides, the significant difference could be due to the high root canal centering ability of the rotary PathFiles that cause less modifications of the canal curvature ${ }^{(20)}$ and fewer canal aberrations besides its ability to preserve the original canal shape considerably better than the manual stainless-steel instruments.

The results came in harmony with Topçuoğlu et al. $(2016)^{(20)}$ who verified that the amount of the apically extruded debris was decreased when a glide path using PathFiles was created in curved root canals before canal preparation with rotary and reciprocating file systems. 


\section{Conclusions:-}

Within the limitation of this in-vitro study, the following conclusions could be drawn; Although all systems caused apical extrusion of debris, the multi-file continuous rotational system is promising and reliable approach to prepare the root canal. The mechanical glide path files are reliable adjunct in reducing the amount of the apical extrusion of debris when used with multiple file continuous rotation system.

\section{Conflict of Interest:-}

The study was partially funded by the National Research Center, Egypt. Other than that, authors deny any conflicts of interest in this study.

\section{References:-}

1. Wu H, Peng C, Bai Y, Hu X, Wang L, Li C. Shaping ability of ProTaper Universal, WaveOne and ProTaper Next in simulated L-shaped and S-shaped root canals. BMC Oral Health. 2015;1:15-27.

2. Rao NK, Kandaswamy R, Umashetty G, Rathore SPV, Hotkar C, Patil SB. Post-obturation pain following onevisit and two-visit root canal treatment in necrotic anterior teeth. J Int Oral Health. 2014; 6(2): 28-32.

3. Shivanna V, Nilegaonkar R. The effect of two continuous rotary and one reciprocating file systems on the incidence of postoperative pain after single-visit endodontic treatment. Int J Oral Health Sci. 2015;5:4-8.

4. De-Deus G, Neves A, Silva EJ, Mendonça TA, Lourenço C, Calixto C, Lima EJ. Apically extruded dentin debris by reciprocating single-file and multi-file rotary system.Clin Oral Investig. 2015;19(2):357-61.

5. Ruddle CJ. Single-FileShapingTechnique: Achieving a GoldMedalResult.Dent Today.2016;35(1):98, 100, 1023.

6. Pasqualini D, Mollo L, Scotti N, Cantatore G, Castellucci A, Migliaretti G, Berutti E. Postoperative Pain after Manual and Mechanical Glide Path: A Randomized Clinical Trial. J Endod. 2012; 38:32-6.

7. Schneider S.W. A comparison of canal preparations in straight and curved root canals. Oral Surg Oral Med Oral Pathol. 1971;32(2):271-5.

8. Fairbourn DR, McWalter GM, Montgomery S. The effect of four preparation techniques on the amount of apically extruded debris. J Endod. 1987;13(3): 102-8.

9. Myers GL, Montgomery S. A comparison of weights of debris extruded apically by conventional filling and canal master techniques. J Endod. 1991;17(6):275-9.

10. Surakanti JR, Venkata RP, Vemisetty HK, Dandolu RK, Jaya NM, Thota S. Comparative evaluation of apically extruded debris during root canal preparation using ProTaper, Hyflex and Waveone rotary systems. J Conserv Dent. 2014;17:129-32.

11. Sowmya HK, Subhash TS, Goel BR, Nandini TN, Shilpa H, Bhandi SH. Quantitative assessment of apical debris extrusion and intracanal debris in the apical third, using hand instrumentation and three rotary instrumentation systems.J ClinDiagn Res. 2014;8(2):206-10.

12. Abdallah MA, Zaazou AM, Mokhless NA. A comparative study of the amount of apically extruded debris after using different types of glide path files. Alex Dent J. 2017; 42:80-4.

13. Koçak MM, Çiçek E, Koçak S, Sağlam BC, Yılmaz N. Apical extrusion of debris using ProTaper Universal and ProTaper Next rotary systems. IntEndod J. 2015;48(3):283-6.

14. Hoppe CB, Bottcher DE, Justo AM, So MV, Grecca FS. Comparison of curved root canals preparation using reciprocating, continuous and an association of motions. Scanning. 2016;38:462-8.

15. Yeter KY, Evcil MS, Ayranci LB, Ersoy I. Weight of apically extruded debris following use of two canal instrumentation techniques and two designs of irrigation needles. IntEndod J. 2013;46:795-9.

16. Nevares G, Xavier F, Gominho L, Cavalcanti F, Cassimiro M, Romeiro K, Alvares P, Queiroz G, Sobral AP, Gerbi M, Silveira M, Albuquerque D.Apical Extrusion of Debris Produced during Continuous Rotating and Reciprocating Motion.ScientificWorldJournal. 2015;2015:267264.

17. Jindal R, Singh S, Gupta S, Jindal P. Comparative evaluation of apical extrusion of debris and irrigant with three rotary instruments using crown down technique-An in vitro study. J Oral BiolCraniofac Res. 2012;2(2): $105-9$.

18. Uzunoglu E, Turker SA, Görduysus M. Effects of Different Rotary Files Combined with Different Irrigation Needles on Apically Extruded Debris. Braz Dent J. 2015;26(4):347-50.

19. Pawar AM, Pawar MG, Metzger Z, Kokate SR. The self-adjusting file instrumentation results in less debris extrusion apically when compared to WaveOne and ProTaper NEXT. J Conserv Dent. 2015;18(2):89-93. 
20. Topçuoğlu HS, Zan R, Akpek F, Topçuoğlu G, Ulusan Ö, Aktı A, Düzgün S, Ağırnaslıgil M.Apically extruded debris during root canal preparation using Vortex Blue, K3XF, ProTaper Next and Reciproc instruments.IntEndod J. 2016;49(12):1183-7.

21. Kirchhoff AL, Fariniuk LF, Mello I.Apicalextrusion of debris in flat-oval root canals after using different instrumentation systems. J Endod. 2015;41(2):237-41.

22. Verma M, Meena N, Kumari RA, Mallandur S, Vikram R, Gowda V. Comparison of apicaldebrisextrusion during root canal preparation using instrumentation techniques with two operating principles. An in vitro study. J Conserv Dent. 2017;20(2):96-9.

23. Çiçek E, Koçak MM, Koçak S, Sağlam BC, Türker SA. Postoperative pain intensity after using different instrumentation techniques: a randomized clinical study. J Appl Oral Sci. 2017;25(1):20-6.

24. Elmsallati EA, Wadachi R, Suda H. Extrusion of debris after use of rotary nickel titanium files with different pitch: A pilot study. AustEndod J. 2009;35(2):65-9.

25. Robinson JP1, Lumley PJ, Cooper PR, Grover LM, Walmsley AD. Reciprocating root canal technique induces greater debris accumulation than a continuous rotary technique as assessed by 3 -dimensional micro-computed tomography. J Endod. 2013;39(8):1067-70.

26. Bürklein S, Schäfer E. Apically extruded debris with reciprocating single-file and full-sequence rotary instrumentation systems. J Endod. 2012; 38: 850-2.

27. Abou El Nasr HM, Gawdat SI. Debris extrusion from severely curved root canals after instrumentation with WaveOne Gold or OneShape single files. Egypt Dent J. 2017;63(3):53-9.

28. Tomer AK, Mangat P, Mullick S, Dubey S, Chauhan P, Kumari A, Rana S, Vaidya S. Quantitative Evaluation of Apically Extruded Debris of Different Single File Systems: Wave One Gold, One Shape, F360, and Reciproc: An in vitro Study. IJOCR. 2017;5(1):1-3.

29. Uzun I, Güler B, Özyürek T, Tunç T. Apical extrusion of debris using reciprocating files and rotary instrumentation systems. Niger J ClinPract. 2016;19:71-5.

30. Van der Vyver P, Vorster M.WaveOne Gold reciprocating instruments: clinical application in the private practice: Part 1. Int Dentistry - African edition. 2017;7(4): 6-19.

31. Ruddle CJ, Machtou P, West JD. The shaping movement: fifth-generation technology. Dent Today. 2013;32(4):94, 96-9.

32. Karataş E, Ersoy İ, Gündüz HA, Uygun AD, Kol E, Çakıcı F. Influence of Instruments Used in Root Canal Preparation on Amount of Apically Extruded Debris. Artif Organs. 2016;40(8):774-7.

33. Yared G. Canal preparation using only one Ni-Ti rotary instrument: preliminary observations. IntEndod J. 2008;41:339-44.

34. Dincer AN, Guneser MB, Arslan D. Apical extrusion of debris during root canal preparation using a novel nickel-titanium file system: WaveOne gold. J Conserv Dent. 2017;20:322-5.

35. Jain D, Medha A, Patil N, Kadam N, Yadav V, Jagadale H. Shaping Ability of the Fifth Generation Ni-Ti Rotary Systems for Root Canal Preparation in Curved Root Canals using Cone-Beam Computed Tomographic: An In Vitro Study. J Int Oral Health. 2015; 7: 57-61.

36. Çiçek E, Akkocan O, Furuncuoglu F. Comparison of apically extruded debris associated with several nickeltitanium systems after determining working length by apex locator. J Conserv Dent. 2016;19(1):68-71.

37. Costa EL, Sponchiado-Júnior EC, Garcia LFR, Marques AAF. Effect of large instrument use on shaping ability and debris extrusion of rotary and reciprocating systems. J InvestigClin Dent. 2018;9(1) :e12289.

38. Koçak MM, Çiçek E, Koçak S, Sağlam BC, Furuncuoğlu F.Comparison of ProTaper Next and HyFlex instruments on apical debris extrusion in curved canals.IntEndod J. 2016;49(10):996-1000.

39. Ozsu D, Karatas E, Arslan H, Topcu MC. Quantitative evaluation of apically extruded debris during root canal instrumentation with ProTaper Universal, ProTaper Next, WaveOne, and self-adjusting file systems. Eur J Dent. 2014;8(4):504-8.

40. Silva EJ, Carapiá MF, Lopes RM, Belladonna FG, Senna PM, Souza EM, De-Deus G. Comparison of apically extruded debris after large apical preparations by full-sequence rotary and single-file reciprocating systems. IntEndod J. 2016;49(7):700-5.

41. Ha JH, Kim SK, Kwak SW, El Abed R, Bae YC, Kim HC. Debris extrusion by glide-path establishing endodontic instruments with different geometries. J Dent Sci. 2016;11:136-40.

42. Abdallah MA, Zaazou AM, Mokhless NA. A comparative study of the amount of apically extruded debris after using different types of glide path files. Alex Dent J. 2017; 42:80-4.

43. Madhusudhana K, Mathew VB, Reddy NM. Apical extrusion of debris and irrigants using hand and three rotary instrumentation systems - An in vitro study. ContempClin Dent. 2010;1(4):234-6.

44. Dhingra A, Neetika. Glide path in endodontics. Endodontology. 2014; 26(1): 217- 22. 
45. Dass A, Saxena A, Chandak M, Bhatia C, Shrivastava S.Quantatitative assessment of apical debris extrusion in apical third using two different NiTi rotary systems- An in vitro study. IJOHD.2016; 2(4):220-3.

46. Türker SA, Koçak S, MuratKoçak M, Sağlam BC. Effect of glide path preparation on apical debris extrusion of rotary and reciprocating single-file systems: OneShape versus WaveOne. Cumhuriyet Dent J. 2015;18(1):1-8.

47. Pawar AM, Pawar M, Kfir A, Thakur B, Mutha P, Banga KS.Effect of glide path preparation on apical extrusion of debris in root canals instrumented with three single-file systems: An ex vivo comparative study.J Conserv Dent. 2017;20(2):110-4.

48. Chandrasekhar M, Reddy SNL, Moosani GK, Reddy NU, Nikhita K, Kumar MP. Influence of Rotary and reciprocating glide path techniques on the incidence of dentinal crack formation- an in vitro study. IJCMR. 2016;3(7):2075-8.

49. Van der Vyver P. Creating a glide path for rotary NiTi instruments: part one. Int Dentistry SA. 2011; 13(2): 610.

50. Ruddle CJ, Machtou P, West JD.Endodontic canal preparation: endodontic canal preparation: new innovations in glide path management and shaping canals. Dent Today. 2014;33(7):118-23.

51. Labbaf H, Shakeri L, Orduie R, Bastami F. Apical Extrusion of Debris after Canal Preparation with Hand-Files Used Manually or Installed on Reciprocating Air-Driven Handpiece in Straight and Curved Canals.Iran Endod J. 2015;10(3):165-8.

52. Üstün Y, Çanakçi BC, Dinçer AN, Er O, Düzgün S. Evaluation of apically extruded debris associated with several Ni-Ti systems. IntEndod J. 2015;48(7):701-4. 